\title{
PARA ENTENDER AL MÉXICO EMERGENTE: DERECHOS HUMANOS, DEMOCRACIA Y VIOLENCIA
}

\author{
TO UNDERSTAND THE EMERGING MEXICO: HUMAN RIGHTS, \\ DEMOCRACY AND VIOLENCE
}

\author{
Samuel F. Velarde \\ Instituto Tecnológico de Ciudad Juárez. México/Mexico \\ samuelfvelarde@gmail.com
}

Recibido/Received: 21/09/2015

Modificado/Modified: 04/10/2015

Aceptado/Accepted: 09/10/2015

\section{RESUMEN}

Los Derechos Humanos, la democracia y la violencia han sido en los últimos quince años las variables que preocupan en el análisis social de México, no se puede comprender la realidad mexicana si no se entiende la intersección de tales variables y lo que provoca en el contexto nacional. Este artículo aborda desde una perspectiva descriptiva y analítica, cómo cada uno de estos elementos mencionados permite enfocar y entender la actual coyuntura por la cual atraviesa el país y por lo tanto visualizar el futuro sociopolítico del país, en un siglo XXI que parece complejo y lleno de inéditas vicisitudes.

\section{PALABRAS CLAVE}

Derechos Humanos, violencia, democracia, sociedad civil, Estado.

\section{SUMARIO}

1. Introducción. 2. Los Derechos Humanos en México, discurso y realidad. 3. La democracia endeble. 4. La violencia generalizada. 5. El retorno del PRI, los resultados. 6. Conclusiones. Bibliografía.

\begin{abstract}
Human Rights, democracy and violence have been in the past fifteen years the variables that concern in social analysis of Mexico, Mexican reality can't be understood if the intersection of these variables and what causes the national context are not understood. This article addresses from a descriptive and analytical perspective, how each of these mentioned elements allows focusing and understanding of the current situation by which crosses the country and therefore display the sociopolitical future of the country in a century that seems complex and full of unpublished vicissitudes.
\end{abstract}

\section{KEYWORDS}

Human Rights, violence, democracy, civil society, state.

\section{CONTENTS}

1. Introduction. 2. Human Rights in Mexico, discourse and reality. 3. The weak democracy. 4. Widespread violence. 5. The return of the PRI, results. 6. Conclusions. References. 


\section{INTRODUCCIÓN}

Algunos gobiernos latinoamericanos, se han enfrentado en los últimos quince años a una violencia generalizada producto de la lucha contra el crimen organizado, esto origina que se fragilice el estado de derecho y que la sociedad civil, quede prácticamente en medio de una cruenta batalla que al parecer, no se le ve un final prometedor. El caso de Colombia y en los últimos quince años el de México, son los ejemplos más significativos de la interminable lucha entre las autoridades y las bandas del crimen organizado. Más allá de la pugna intercarteles por la comercialización de las drogas, existen causas estructurales que han permitido el crecimiento de esta problemática como lo son: la pobreza extrema, la corrupción y la impunidad entre otras. Pero también este tipo de violencia es un factor que inhibe a la democracia, al convertirla en un postulado y práctica endebles, lo más grave del asunto es que vulnera los Derechos Humanos, pues en un estado de violencia sistemática y sistémica, los ciudadanos se ven sumergidos en un medio social enrarecido, donde las garantías individuales comúnmente son afectadas y las instituciones de impartición de justicia, son partícipes de la corrupción o se vuelven disfuncionales.

El presente trabajo aborda la problemática de los Derechos Humanos, la democracia y la violencia en México, como el marco contextual de un país que se debate en una coyuntura difícil y que para lograr entenderla, en mucho radica analizar tales problemáticas. Igualmente, se intenta vislumbrar qué perspectivas en el futuro inmediato se esperan en un escenario como el aquí expuesto. Lo positivo de este fenómeno, es que ha motivado la participación de una sociedad civil que tímidamente intenta ganar los espacios perdidos o generar otros más novedosos, en su lucha por una sociedad menos violenta y más incluyente.

El análisis presentado es descriptivo y de coyuntura bajo la óptica sociológica, asumiendo el análisis de coyuntura como "al nivel más inmediato de la realidad social, al espesor de superficie, y a un segmento de tiempo corto especifico, aquel donde se condensa tiempo social" (Osorio, 2008).Pero también basándose en los hechos de la historia cotidiana, que acercan al lector a una circunstancia que da para la reflexión multidisciplinaria y con la presencia del autor, como diría Foucault (2010:12)."En la escritura ... se trata de la apertura de un espacio donde el sujeto que escribe no deja de desaparecer".

\section{LOS DERECHOS HUMANOS EN MÉXICO, DISCURSO Y REALIDAD}

El 10 de diciembre de 1948 se aprobó por parte de la Asamblea General de las Naciones Unidas la Declaración Universal de Derechos Humanos, desde ese momento hasta la década de los ochenta, los Derechos Humanos se veían como un postulado de corte humanista y meramente teórico y, eventualmente, se suponía que eran respetados. Sin embargo, a partir del proceso de globalización se ha generado un el intercambio de ideas (aparte de mercancías), que ha facilitado un mayor conocimiento de estos derechos a nivel mundial, y si la vuelta al mundo la dan las mercancías en un libre comercio, el tema de los Derechos Humanos también, y es preocupante la manera en que tanto gobiernos como organismos internacionales -unos más que otros-, así como por otras instancias no gubernamentales se apropian de ellos. La intercomunicación global (Castells, 2006) permite conocer la situación de miles de personas víctimas del poder en cualquier región, obligando a poner un mayor interés al respecto, aparte de que las diversas instancias democráticas motivan la discusión sobre los Derechos Humanos.

Entonces, los Derechos Humanos adquieren una connotación más allá de lo jurídico para convertirse en un concepto epistemológico más abarcador. "Un primer desafío radica en la 
necesidad de una aproximación multidisciplinaria a los Derechos Humanos, tendencia que opera facilitada por el debilitamiento de la tradicional hegemonía de la perspectiva jurídica" (Arias, 2011:20). Varios gobiernos como el mexicano, se ven presionados y señalados por organizaciones internacionales como Naciones Unidas, Amnistía Internacional, Comisión Interamericana de Derechos Humanos, Disability Rights Internacional y Human Rights Watch para resolver situaciones de violación a los Derechos Humanos o recomendaciones para mejorar las políticas públicas relacionadas con los mismos.

En el caso particular de México, los Derechos Humanos se han vulnerado de manera sistemática, más allá de los compromisos del discurso oficial y del Estado al adherirse a mecanismos internacionales. México, usando un conocido adagio popular, era una especie de "candil de la calle oscuridad de su casa", pues mientras tuvo una política exterior de apoyo a los perseguidos políticos extranjeros otorgándoles asilo-situación que le dio prestigio como país-, al interior eran constantemente reprimidos los disidentes políticos y callada cualquier voz contestataria que infringiera el statu quo.

En 1999 se crea la Comisión Nacional de los Derechos Humanos (CNDH), una institución autónoma del Estado y bajo la dirección de un ombudsman. La tarea de la CNDH no fue fácil, sobre todo en un país donde el régimen autoritario había dejado una estela de cultura antidemocrática y de violación de las garantías individuales durante sus gobiernos, asimismo la existencia de una serie de poderes fácticos (grupos políticos regionales, grupos económicos, crimen organizado), refuerzan y reproducen esa práctica violatoria. El indígena, el campesino, los disidentes políticos y el trabajador pobre, fueron y son víctimas recurrentes de este sistema.

Lo positivo de la creación de la CNDH, fue la difusión de una cultura de respeto a los Derechos Humanos entre la población y de implantar de forma paulatina, la cultura de la legalidad. Es necesario recalcar que el interés del Estado mexicano por auspiciar una instancia defensora de los Derechos Humanos, tiene que ver en mucho con la mala imagen del país en el exterior. Por otro lado, su inserción en el Tratado de Libre Comercio para América del Norte (TLCAN) en 1994, obligó a dar la impresión que la modernización que se iniciaba no solamente era en el sentido económico y tecnológico, sino también en el sentido social. Por supuesto que la presión de los grupos organizados de organizaciones de la sociedad civil y organizaciones no gubernamentales, es un factor digno de considerarse.

En la práctica, los Derechos Humanos en México se han visto limitados no solamente por la violencia generalizada y sus secuelas, sino también por la gran impunidad existente, que tiene que ver la corrupción en algunas esferas gubernamentales y con la no aplicación de las leyes, que impiden la transparencia y la rendición de cuentas. Frank La Rue (2012), relator de la ONU para la libertad de expresión, comentó refiriéndose al actual gobierno mexicano: "El desafío más importante del próximo gobierno de México será erradicar la impunidad y hacer de la investigación penal algo ágil, eficiente y real además de la sanción a los responsables".

Estos elementos fueron el contexto socio-político que sirvieron de entramado, para que de forma limitada se desarrollase la transición democrática mexicana de finales del siglo pasado y que explican el origen fallido de conseguir un Estado de derecho más consolidado y fértil.

\section{LA DEMOCRACIA ENDEBLE}

La transición democrática de México en los años ochenta fue un proceso difícil y lleno de vicisitudes, es resultado de un sistema político que comienza a deteriorarse, asimismo producto de la ardua lucha por una democracia que se intentó construir sobre todo a partir del 
movimiento estudiantil de 1968, donde se van organizando una serie de grupos sociales de muy diversa índole (campesinos, trabajadores, mineros, burócratas, maestros, estudiantes, e intelectuales), incluso de grupos que vieron en la lucha armada, la única opción válida para el cambio. Así, el proceso de transición que termina con la alternancia en el poder en el 2000 al asumir el Partido Acción Nacional (PAN)la presidencia de la república, es un complejo resultado de innumerables acciones político-sociales y de respuestas en más de una vez represivas por parte del Estado mexicano, que fueron dándole forma a la incipiente democracia. Sin embargo, con una sociedad civil en ciernes y de escasa posibilidad de maniobrar un mejor empoderamiento a su favor.

El 1 diciembre de 2006 Felipe Calderón nuevamente del PAN, asume la presidencia con un margen de votos muy reducido sobre el candidato de la izquierda Andrés Manuel López Obrador del Partido de la Revolución Democrática (PRD), era el segundo sexenio panista. Buena parte de la sociedad civil mexicana se quedó con la duda sobre los resultados electorales, creándose un ambiente polarizado y de incredulidad hacia las instituciones electorales. El 11 de diciembre del mismo año, el presidente Calderón declara la guerra al crimen organizado, como respuesta a la ola de violencia que se había vuelto cotidiana sobre todo en los estados norteños del país: Chihuahua, Tamaulipas, Coahuila y Nuevo León principalmente, aunque después se extendería a Michoacán y al estado sureño de Guerrero, éste con una tradición de lucha guerrillera desde los años sesenta. La declaración de guerra fue sin miramientos, pronto se olvidó entre la población el conflicto postelectoral y ciertas regiones del país quedaron repentinamente metidas en un campo de batalla.

A pesar de la alternancia en el poder y de la democracia electoral que México inauguró en el 2000, continuaron existiendo vestigios de intolerancia política impuesta por la clase política mexicana, acostumbrada a gobernar en ese terreno, que de alguna forma detona acciones violentas de grupos pro establishment. La represión de Atenco (bajo el gobierno de la alternancia) en el Estado de México en el 2006, ha sido la prueba de que no se quiso cambiar la estrategia autoritaria del establishment mexicano, dicha represión se da por la oposición de los campesinos del lugar, a la construcción del aeropuerto internacional alterno al de la Ciudad de México. Así, la democracia se fue quedando en el discurso con un escaso significado de justicia entre la sociedad civil, incluso subestimándose su valor político. Para Hernández (2008) el poco interés y conocimiento de la política; el bajo nivel de confianza interpersonal $\mathrm{y}$ en las instituciones; la poca tolerancia y la discriminación actual hacia diversos sectores (entre ellos, minorías religiosas, mujeres, discapacitados, adultos mayores, indígenas y personas no heterosexuales), así como la exigua competencia subjetiva, influyen en la escasa participación política de los mexicanos, además de que permite la persistencia de rasgos autoritarios como los corporativos y clientelares, los cuales no fortalecen la democracia.

Bajo esta perspectiva, el Estado mexicano se convierte no en un aliado o representante de la sociedad civil a través de sus gobernantes, sino más bien da la impresión que actúa como una entidad sumamente controladora y coactiva, no alcanza un nivel de compromiso democrático más amplio con sus gobernados, ni siquiera intenta mantener los canales de comunicación pertinentes para escuchar a la sociedad o abrir otras vías más eficientes, que redundaran en un diálogo permanente y sembrar una confianza mutua.

\section{LA VIOLENCIA GENERALIZADA}

México es un puente geográfico en el recorrido que hacen los diferentes tipos de drogas hacia su destino final: Estados Unidos y últimamente Canadá, pero también se ha convertido 
en un importante consumidor. Desde la década de los ochenta y noventa del siglo pasado, lo anterior era una premisa conocida en el ámbito de la seguridad nacional, el fortalecimiento de los cárteles mexicanos y la impunidad con que trabajan coludidos con autoridades corruptas, permite que entrando el siglo XXI las organizaciones criminales se conviertan en verdaderos emporios económicos y con una gran capacidad en el uso de la violencia. Al asumir Calderón la presidencia, el poder del narcotráfico mexicano ya había echado importantes raíces en la mayoría del territorio nacional. Por ello la tesis de que la declaración de guerra por parte del nuevo gobierno, pone en grandes aprietos a una democracia que en la formalidad, apenas cumplía seis años de vida y se encontraba en proceso de construcción. Según Hurtado (2012:s.n) "El sistema democrático de leyes e instituciones que construimos durante el último tercio del siglo XX ahora nos parece una estructura hueca que no cambió a fondo nuestra realidad. En efecto, la corrupción, la simulación y la incompetencia siguen infectando nuestro sistema político".

La respuesta del Estado mexicano a la violencia, se basó principalmente en el despliegue de la policía federal y posteriormente usando a las fuerzas armadas que intentan recuperar el supuesto orden perdido. Pearce comenta (1980: 99) "El criterio que determina la intervención estatal es la medida en que las actividades minan el orden social. La imagen convencional de ese orden social es ideológica, en el sentido de que presenta, de manera parcial, el funcionamiento de la sociedad a la vez que oculta la naturaleza "real" del orden social." Así, el gobierno de Felipe Calderón asume la responsabilidad de devolver la tranquilidad al país, creando todo un discurso que justifique la acción policiaco-militar. Indudablemente que los resultados fueron al principio inhibidores para el crimen organizado, aunque posteriormente se vio la gran fuerza de los grupos delictivos y la debilidad de una policía federal sin adiestramiento, igualmente un ejército al que se le dificulta combatir fuera de las estrategias de la guerra convencional para el cual fue capacitado. Hay que recalcar que al interior de las fuerzas armadas hubo un rechazo a tal estrategia por parte de algunos altos oficiales de alto rango, pero que se diluye por la misma naturaleza vertical de la disciplina militar al acatar órdenes superiores, más si provienen del presidente de la república como comandante en jefe.

La justificación del discurso gubernamental para enfrentar al crimen organizado en voz del presidente Calderón, es que el narcotráfico creció desmesuradamente en los anteriores gobiernos sin que nadie los combatiera, dando a entender la responsabilidad que tuvieron las administraciones emanadas del PRI. Por otro lado, es un hecho que el gobierno estadounidense avaló esta guerra contra el crimen organizado, otorgándole al gobierno mexicano ayuda en logística y tecnología militar, según Ojeda (2010).

A pesar de ello, el gobierno estadounidense nunca ha aceptado su responsabilidad en el problema del narcotráfico, argumentando que la culpa es de los pushes y no de los consumers. O sea de los vendedores y no de los consumidores. En pocas palabras, para ellos la causa del problema radica en la oferta y no en el consumo. Fue hasta abril de 2009, durante la primera visita de Barack Obama a México, que un presidente de Estados Unidos aceptó expresa y públicamente la posición de responsabilidad compartida.

Si bien se tomaron medidas de contención a través del gran número de policías y militares desplegados en el país, la violencia adquiere un perfil inusitado, llegando a acciones realmente inhumana donde los grupos criminales tratan de demostrar su poderío usando la psicología del terror para atemorizar a la sociedad. El crimen organizado aprovechando la crisis estructural, se incrusta en sectores empobrecidos para fines de reclutamiento de sicarios y expendedores de drogas, estableciendo un mini mercado, que al cuadricularse en un espacio geográfico, se obtienen ganancias extraordinarias por la venta y el control del 
narcomenudeo. Asimismo, "El gobierno de Calderón desató fuerzas que han terminado por sustraer del poder del Estado a regiones enteras del país, donde los cárteles del narcotráfico imponen su ley, cobran impuestos bajo forma de "protección" o "derecho de piso" a empresas e individuos y ponen o quitan de grado o por la fuerza a alcaldes, jefes de policía, diputados, etcétera" (Solís, 2013:27).

La espiral de violencia se presenta con mayor frecuencia en el norte del país, donde se dan casos de ejecuciones masivas producto de la lucha territorial entre bandas rivales y que bajo este criterio criminal, muchos inocentes mueren. Uno de los hechos que recorrió el mundo, fue el asesinato en enero de 2010 de 18 estudiantes que celebraban una fiesta en una colonia popular llamada Villas de Salvarcar en Ciudad Juárez, ciudad fronteriza con El Paso Texas, donde brutalmente fueron asesinados aparte de varios heridos. Esta masacre obligó al presidente Calderón a visitar la ciudad e implementar un plan urgente llamado Todos somos Juárez para combatir el rezago social a través de programas sociales y obra pública. Más allá de los cientos de relatos en este tenor, la realidad fue que el problema de la violencia generó una constante violación a los Derechos Humanos y vulneró a la incipiente democracia, que ya casi deja de percibirse en el imaginario colectivo de los mexicanos.

El Estado mexicano, no tuvo una estrategia realmente eficaz para el combate al narcotráfico y a los grupos criminales. Se lanzó agresivamente con un aparato policiaco-militar pero sin estrategia previa de inteligencia y sin un entramado jurídico ad hoc, pero lo más grave, con una aprobación social casi nula y con una sociedad que desconocía a ciencia cierta lo que vendría después.

\subsection{La respuesta social}

Bajo tal situación la sociedad civil mexicana se constriñe en su accionar cívico, el miedo por los actos violentos tanto de las fuerzas gubernamentales como de los grupos criminales la acorralan, aunque la violencia no tiene el mismo grado de intensidad en todo el país, si existe un efecto dominó generalizado a propósito de que se palpa miedo y desconfianza. La sociedad se convierte en una entidad petrificada y sin posibilidad de ser escuchada, al menos sucede en la mayoría de las ciudades donde la violencia es más recurrente. Se puede afirmar que la cohesión social sufre una decaída fuerte, se pierde la confianza social y se nulifica la posibilidad de generar un capital social (Putnam, 1993, 2011) que fortificara al tejido social. Una de las consecuencias de este fenómeno es que en varias ciudades se da un proceso de fragmentación social, las colonias de clase media se aíslan construyéndose murallas a su alrededor o contratando servicios de seguridad privada, con el fin de evitar ser víctimas de la violencia. Creándose "espacios vitales" de sobrevivencia que cercenan la intercomunicación y fragmenta todavía más, a una sociedad diezmada por el miedo.

A pesar de todo, la sociedad civil mexicana fue generando respuestas de manera tímida y limitada, se organizaron pequeños grupos sociales para exigir justicia, reclamar por la desaparición de personas, protestar contra el abuso de autoridades y principalmente contra los feminicidios en Ciudad Juárez, entre 2009 y 2010 se registraron en esta ciudad 469 feminicidios (La Jornada, 2011). Desafortunadamente muchas de las personas que se organizaron para protestar en este sentido, fueron posteriormente amagadas o asesinadas en represalia por sus constantes denuncias, es el caso de la activista Marisela Escobedo, que es asesinada frente al palacio de gobierno del estado de Chihuahua en 2010.

Uno de los reclamos que dieron origen a una movilización nacional más estructurada y al nacimiento del Movimiento por la Paz con Justicia y Dignidad, fue el asesinato en el 2011 de Juan Francisco Sicilia, hijo del poeta y periodista Javier Sicilia en Cuernavaca México, hecho que desencadenó una serie de protestas a nivel país, poniendo en tela de juicio la credibilidad 
en las autoridades y la manera como habían enfrentado a las bandas del crimen organizado. Este movimiento sacudió conciencias y tuvo un efecto multiplicador a lo largo y ancho de México, pues los miles de familiares de personas desaparecidas o muertas se sumaron al sentir de la movilización, que exigía el fin de este enfrentamiento para muchos sin sentido. Las autoridades federales se vieron obligadas a pedir disculpas por las víctimas inocentes pero no desistieron de su plan anti crimen. La estrategia política de la Marcha por la Paz, fue la de convocar al diálogo entre los poderes de la nación, hubo reuniones con el presidente de la república, con diputados y senadores, el diálogo fue un reclamo continuo a la política del Estado. De aquí nació la iniciativa de indemnizar a aquellos que habían perdido a sus familiares en esta espiral de violencia a través de la Ley General de Victimas, dicha Ley se publicó el 9 de enero del 2013 en el Diario Oficial de la Federación, sin embargo hasta la fecha, aún no se sabe cómo se va a instrumentar dicha ley.

El fenómeno de la violencia acarreó 60.000 muertos, 27.000 desaparecidos (Amnistía Internacional, 2013), cientos de madres sin sus hijos y miles de familias desintegradas. Todo un Estado anómico diría Durkheim (1998), que pone en entredicho a la misma axiología social y cultural del país. Donde repentinamente se pierde la concepción ética de la realidad, padeciéndose una confusión en términos de lo que es bueno y malo. En otras palabras, no solamente se fragiliza un Estado de derecho sino también el entramado ético y humanista de una sociedad que apenas comenzaba a construirse una perspectiva democrática.

Por si fuera poco, la corrupción y la impunidad son dos elementos que han carcomido a las instituciones judiciales del país, estas se han visto cooptadas y corrompidas por grupos criminales o poderes fácticos que obstaculizan la práctica transparente de la justicia y terminan por violentar el Estado de derecho. Así, el Estado mexicano como entidad se enfrenta a sí mismo, dividido en grupos más o menos institucionales y democráticos, contra otros involucrados en intereses poco claros y hasta ilegales.

\section{EL RETORNO DEL PRI, LOS RESULTADOS}

Luego de las elecciones de julio del 2012, donde el PRI recupera la presidencia de la república con Enrique Peña Nieto, los Derechos Humanos, la democracia y la violencia se convierten en temas sensibles, pues el rezago en las políticas públicas que sostengan un entramado de justicia y de calidad de vida en los mexicanos, es todavía un problema a resolver. Hay en el país 55.3 millones de personas sumidos en la pobreza, según el Consejo Nacional de Evaluación de la Política de Desarrollo Social (CONEVAL) aunado al informe nada halagüeño que recientemente presenta la OCDE "Midiendo el bienestar de los Estados Mexicanos", en donde se califica de mediocres los indicadores de bienestar y compara las diferencias entre algunos estados del sur con otros del norte del país, donde la desigualdad estructural es notable (OCDE, 2015). Situación que obstaculiza el funcionamiento de una democracia incluyente pues deteriora la participación ciudadana y el ejercicio de sus derechos, de igual forma la impartición de justicia se ha puesto en entredicho en varias ocasiones, acrecentando la incertidumbre sobre la legalidad y vulnerando las garantías sociales.

La estela de violencia que hereda el gobierno del presidente Peña Nieto continúa su curso, con organizaciones criminales más fortalecidas, pues en la medida de que se les combate y se daña su estructura, se multiplican por varias partes. Sin dejar de lado el hecho de que el gobierno se empecina en continuar casi la misma estrategia del sexenio anterior, que se niega a escuchar a un sector social plural que demanda una mejor estrategia en seguridad pública. 
Socialmente el deterioro del país es algo que debe aceptarse sin vergüenza, más bien con preocupación, se necesita abrir espacios de diálogo y romper con lo monolítico de las elites políticas. Algo que debe alertar al Estado y a la sociedad, es que se avista una sociedad con un gran sector lumpen, un sector que se ha desarrollado como consecuencia de la miseria y la injusticia social, que recurre a la ilegalidad para sobrevivir bajo la sombra de la violencia y la indolencia social, este sector lumpen desquebraja no solamente la legalidad, sino que también permea culturalmente a la población, con el riesgo de ir propiciando fenómenos tipo maras salvatruchas salvadoreñas o el sicariato juvenil colombiano. En México existen 7 millones de jóvenes que ni estudian ni trabajan entre un rango de edad de 16 a 29 años (La Jornada, 2015). Y bajo estas condiciones sociales, políticas y económicas, se observa muy difícil la pronta construcción de un Estado de derecho efectivo y de una sociedad civil más participativa, o incluso el éxito de un proyecto político diferente.

Aunque en la ley se acepta que México es un país multicultural y étnicamente heterogéneo, el respeto a los Derechos Humanos y el funcionamiento de la democracia participativa siguen siendo asuntos pendientes como elementos de equilibrio y diálogo, sobre todo para mantener la gobernabilidad y la institucionalidad del país.

La sociedad mexicana se encuentra en un punto de semipetrificación, no existen indicios de movilizaciones sociales de cierta magnitud que llamen la atención del Estado y se le obligue a buscar los canales institucionales para ir mejorando el aspecto legal, pues la movilización social (Touraine, 1997), ha sido la estrategia organizativa de la sociedad civil en cualquier parte del mundo, para demostrar el desaliento ante cualquier política estatal errada o ante la injusticia del poder cualquiera que sea su fuente. Si bien las movilizaciones se dan de forma escasa, la sociedad manifiesta su inconformidad con otras conductas políticas. En las elecciones que se llevaron a cabo el 2014, para elegir diputados federales, estas fueron desairadas en un buen porcentaje, deteriorando un instrumento que se supone fortalece a las instituciones y promueve la democracia y la participación ciudadana. Tal fenómeno puede interpretarse como una desilusión del ciudadano a una democracia que no se le ven resultados eficientes, pero también a un proceso electoral amañado y lleno de irregularidades, donde la pobreza se sigue explotando para acarrear votos, para Hernández (2009:136) "Es así como la rentabilidad política de los políticos se construye a partir de su capacidad por allegarse a la gente, aunque su imagen dependa de subsidios, intercambios ilegales y mecenazgos, no de proyectos que pretendan el desarrollo de su comunidad". Además de que se perciben ciertas dudas en relación al financiamiento delas campañas de varios políticos locales.

El momento actual de México es preocupante, ya que se mueve en un contexto lleno de contradicciones, que van desde la arquitectura del mismo sistema político y con una elite política muy recalcitrante a los cambios, hasta una sociedad que aún no encuentra la suficiente cohesión social para promoverlos de forma más profunda y sustanciosa, donde la participación ciudadana sea el eje en la construcción de un país de mayor certidumbre, igualdad y democracia. Aunado a una despolitización constante que es el resultado de un divorcio entre la sociedad civil y los partidos políticos.

A raíz de los 43 desaparecidos de Ayotzinapa en el estado de Guerrero, acontecimiento que ha puesto al gobierno mexicano en jaque por su tardía y débil respuesta al caso, en donde la intermitente movilización popular y la denuncia internacional han tenido la fuerza para presionar y tratar de lograr aclarar este asunto, ha sido un factor más que complejiza la realidad mexicana, tanto que el Grupo Interdisciplinario de Expertos Independientes (GIEI) (GIEI,2014), designados por la Comisión Interamericana de Derechos Humanos, se ha encargado de presentar un informe completo sobre los hechos, ya que las conclusiones 
gubernamentales sobre el caso dejaron mucho que desear. En la introducción del Informe Ayotzinapa entre otras cosas se afirma que:

El GIEI lamenta no poder ofrecer a los familiares, al Estado y la sociedad mexicana o al mundo, un diagnóstico definitivo de lo sucedido con los 43 normalistas desaparecidos. Para ello existen numerosas dificultades que se señalan en este informe, pero sí recoge los hechos que considera probados que no han sucedido o sobre los que existe una controversia tal que se cuestiona su validez (Informe, 2015:5).

Aún falta por ver que el régimen realice cambios sustanciales, que beneficien a la construcción de un tejido social más sano y así, fortalecer a la sociedad civil. El descredito de los gobernantes tiene que ver con las razones expuestas arriba, una clase política que desdeña el diálogo público y que no ha entendido de que la modernización no es únicamente un proceso de cambios, que tengan que ver con lo económico y el libre mercado, sino también con el recomponer a la estructura social y darle coherencia a un proyecto de nación aglutinador, no desintegrador.

El factor corrupción por otro lado, es otro componente que se suma a la opacidad del sistema político y sus operantes, haciendo que la legalidad institucional se vea alejada de la realidad mexicana. Para Casar (2015:22) "En el caso de México los niveles de percepción de corrupción en las instituciones consideradas como los pilares de una democracia representativa -partidos políticos y poder legislativo- son extraordinariamente elevados y esto torna más complicada la gobernabilidad pues resta legitimidad a las decisiones de gobierno". Situación que daña a las instituciones y a sus objetivos sociales, debilitando la cultura de la legalidad y al entramado ético de una nación que se ha achicado en su dinámica social.

\section{CONCLUSIONES}

En la sociología, el estudio de las relaciones e instituciones sociales, así como de los diversos actores que interactúan en un sistema social, permite conocer determinadas fenomenologías que se suscitan en su interior. Así, el conflicto obliga, como parte importante de la dinámica social, a continuar analizando los elementos constitutivos del mismo, sus causas y consecuencias, que den como resultado no solamente teorías y el enriquecimiento del pensamiento sociológico, sino también posibles alternativas de análisis y de propuestas.

En el caso mexicano, es un hecho que mientras el conflicto de la dinámica social no tenga salidas institucionales y de diálogo entre sus actores, que permitan buscar soluciones sociales, políticas y económicas a los problemas señalados, se atizará el descontento, en donde por un lado los poderes fácticos continúen aprovechándose del rio revuelto y generando un país con características de ingobernabilidad y por el otro, una sociedad casi en estado de indefensión metida en un remolino de injusticia, impunidad y antidemocracia, dificultando cada vez más la posibilidad de construir un modelo de nación más democrática e incluyente.

\section{BIBLIOGRAFÍA}

ARIAS MARÍN, A. (2011). "Globalización, cosmopolitismo y Derechos Humanos. Apuntes sobre el contexto teórico y la reforma constitucional" en http://www.juridicas.unam.mx/publica/librev/rev/ derhumex/cont/18/art/art2.pdf (consulta 25/7/2015).

CASAR, M.A. (2015). México: Anatomía de la Corrupción. México: CIDE-IMC.

CASTELLS, M. (2006). La sociedad red. Una visión global. Madrid: Alianza Editorial. 
CONEVAL. http://www.coneval.gob.mx/Paginas/principal.aspx (consulta 20/7/2015).

DURKHEIM, E. (1998). El suicidio. Buenos Aires: Grupo Editorial Tomo.

FOUCAULT, M. (2010). ¿Qué es un autor? Córdoba, Argentina: Ediciones literales.

GIEI (2014). Grupo Interdisciplinario de Expertos Independientes, México, en http://centroprodh.org.mx. HERNÁNDEZ, M. A. (2008). "La democracia mexicana, presa de una cultura política con rasgos autoritarios". Revista Mexicana de Sociología, 70 (2), en http://www.scielo.org.mx/scielo.php?pid= S0188-25032008000200002\&script=sci_arttext (consulta 3/7/2015).

HERNÁNDEZ MUÑOZ, E. (2009). "Clientelismo en México, los usos políticos de la pobreza" en F.L. Fernández, et al. (Coords.) Democracia y Derechos Humanos, desafíos para la emancipación. México: Universidad del Estado de México, pp.131-138.

HERNÁNDEZ NAVARRO, L. (2012). “Acteal: impunidad y memoria”, El Cotidiano, 172: 99-115. México: Universidad Autónoma Metropolitana.

HURTADO, G. (2012). "La filosofía y la crisis de México", Este País, nº 250.

INFORME AYOTZINAPA (2015). Grupo Interdisciplinario de Expertos Independientes, en http://centroprodh.org.mx/GIEI/?p=196 (consulta 20/8/2015).

LA JORNADA (2015). "En México, 7 millones de los 39 millones de ninis que hay en naciones de la OCDE", en http://www.jornada.unam.mx/2015/05/28/sociedad/038n1 soc (consulta 2/8/2015).

LA JORNADA (2011). "Registra Juárez en 2010 la cifra más alta de feminicidios en 18 años", en http://www.jornada.unam.mx/2011/01/02/politica/006n1pol (consulta 2/8/2015).

OCDE (2015). Midiendo el bienestar de los Estados Mexicanos, en www.oecd.org/gov/regional-policy (consulta 15/8/2015).

OJEDA GÓMEZ, M. (2010). El combate al narcotráfico: guerra sin fin en sentido contrario. Éste País, en http://estepais.com/site/?p=27547 (consulta 17/8/2015).

OSORIO, J. (2008). Fundamentos del análisis social. México: UAM-FCE.

PEARCE, F. (1980). Los crímenes de los poderosos, el marxismo el delito y la desviación. México: Editorial Siglo XXI.

PUTNAM, R. (2011). "Bowling alone: America's declining social capital" en R.T. Le Gates y F. Stout (eds.) The city reader. New York: Routledge. Urban Readers Series, pp.134-142.

PUTNAM, R. (1993). Making democracy work: civic traditions in modern Italy. Princeton: Princeton U.P. SOLÍS GONZÁLEZ, J. L. (2013). "Neoliberalismo y crimen organizado en México: El surgimiento del Estado narco". Revista Frontera Norte, 25 (50). Colef.

TOURAINE, A. (1997). ¿Podemos vivir juntos? México: Fondo de Cultura Económica.

\section{Breve currículo:}

\section{Samuel F. Velarde}

Licenciado en sociología por la Universidad Autónoma Metropolitana, /Universidad Autónoma de Ciudad Juárez, México. Maestro en Administración por la Universidad Autónoma de Chihuahua, México. Doctor en Relaciones Transpacíficas por la Universidad de Colima, México. Actualmente profesor en el Instituto Tecnológico de Ciudad Juárez. Líneas de investigación: sociedad civil, cultura y estudios coreanos. 